\title{
Efficacy of insect pathogenic fungi on mortality and development of Rhynchophorus ferrugineus (Olivier)
}

\author{
Waqas Wakil ${ }^{1}$, Muhammad Usman ${ }^{2}$ and Sehrish Gulzar ${ }^{2}$ \\ (1) Institute of Agricultural Sciences, University of the Punjab, Quaid-e-Azam Campus, Lahore, Pakistan, \\ email: waqaswakeel@ hotmail.com; (2) Department of Entomology, University of Agriculture, Faisalabad, Pakistan
}

\begin{abstract}
Wakil, W., M. Usman and S. Gulzar. 2019. Efficacy of insect pathogenic fungi on mortality and development of Rhynchophorus ferrugineus (Olivier). Arab Journal of Plant Protection, 37(2): 198-199.

Fifteen different isolates of entomopathogenic fungi including Beauveria bassiana, B. brongniartii, Metarhizium anisopliae and Purpureocillium lilacinum were tested for their effectiveness against different developmental stages of red palm weevil R. ferrugineus. After 21 days of exposure, B. bassiana isolates (WG-23 and WG-25) caused $100 \%$ mortality in larvae while only WG-25 resulted in $100 \%$ mortality

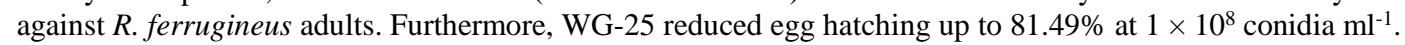

Keywords: Red palm weevil, entomopathogenic fungi, mortality, horizontal transmission, sub lethal effects, progeny.
\end{abstract}

\section{Introduction}

The invasive red palm weevil Rhynchophorus ferrugineus (Olivier) (Coleoptera: Curculionidae) is recognized as one of the most serious threat to date palm plantation (Dembilio and Jaques, 2015; Tagliavia et al., 2014; Wakil et al., 2015). It has been reported in $50 \%$ of date producing countries (ElMergawy and Al-Ajlan, 2011), also it is a serious pest of date palms in Pakistan (Mohan, 1917). The aim of this study is to explore fifteen different isolates of entomopathogenic fungi including Beauveria bassiana, B. brongniartii, Metarhizium anisopliae and Purpureocillium lilacinum against different developmental stages of $R$. ferrugineus.

\section{Screening Bioassays}

During initial screening bioassays, both developmental stages were found susceptible towards all tested 15 isolates causing $14.9-81.5 \%$ and $5.6-51.7 \%$ mortality against larvae and adults, respectively.

\section{Virulence Bioassay}

The most effective top five potential isolates from screening bioassays were further evaluated against $6^{\text {th }}$ instar larvae and adults of $R$. ferrugineus using four different concentrations $\left(1 \times 10^{6} ; 1 \times 10^{7} ; 1 \times 10^{8} ; 1 \times 10^{9}\right.$ conidia $\left.\mathrm{ml}^{-1}\right)$ and mortality was recorded at 7,14 and 21 days after treatment. After 21 days of exposure, WG-23 and WG-25 caused $100 \%$ mortality in larvae while only WG-25 resulted 100\% mortality against adults. The virulence bioassay showed positive correlation with time and concentrations. Our results are in agreement with those of Verde et al. (2015) who showed that $B$. bassiana caused significant mortality against larvae and adults resulting in $88-92 \%$ and $20-26 \%$ mortality, respectively. Similarly, Francardi et al. (2012) tested the entomopathogenic fungi against the larvae and adults of $R$. ferrugineus and observed 100\% and 90\% mortalities, respectively. Likewise, Dembilio et al. (2010) verified that $B$. bassiana can significantly infect the $4^{\text {th }}$ instar larvae and laboratory adults with calculated $\mathrm{LC}_{50}$ values of $6.3 \times 10^{7}$ and $7.2 \times 10^{8}$ conidia $\mathrm{ml}^{-1}$, respectively. We also found that potential isolates were not only effective against larval and adult stages, but also showed ovicidal effects, as WG-25 reduced egg hatching up to $81.49 \%$ at $1 \times 10^{8}$ conidia $\mathrm{ml}^{-1}$. Similar to our results, Dembilio et al. (2010) confirmed that $B$. bassiana considerably infected the eggs of $R$. ferrugineus $\left(\mathrm{LC}_{50} 1.5 \times 10^{8}\right.$ conidia $\left.\mathrm{ml}^{-1}\right)$. Likewise, Verde et al. (2015) evaluated different $B$. bassiana isolates against eggs of red palm weevil and observed $26.8-41.2 \%$ reduction in egg hatching compared with the control.

\section{Auto-dissemination Bioassay}

In auto-dissemination bioassay, it was confirmed that fungal infected adults have ability to transmit the disease to healthy ones. The effective isolate (WG-25) reduced the number of eggs per female/day (0.5 eggs/day), fecundity (11.7 eggs/female), eggs survival $(11.6 \%)$ and larval survival $(25.9 \%)$ when treated males mated with treated females compared with the control treatment. Similarly, Dembilio et al. (2010) proved that B. bassiana caused $>62.6 \%$ and $32.8 \%$ reduction in fecundity and egg hatching, respectively with overall $78 \%$ reduction in progeny among different pairing combinations. The present study revealed that entomopathogenic fungi have a great potential to control the different developmental stages of $R$. ferrugineus and may become an integral part of successful IPM program of date palm insect pests.

\section{Acknowledgements}

We are thankful to Higher Education Commission, Islamabad (Pakistan) for their support (Grant NRPU-3244) to this study. This is a short note, and the detailed results will be published soon. 


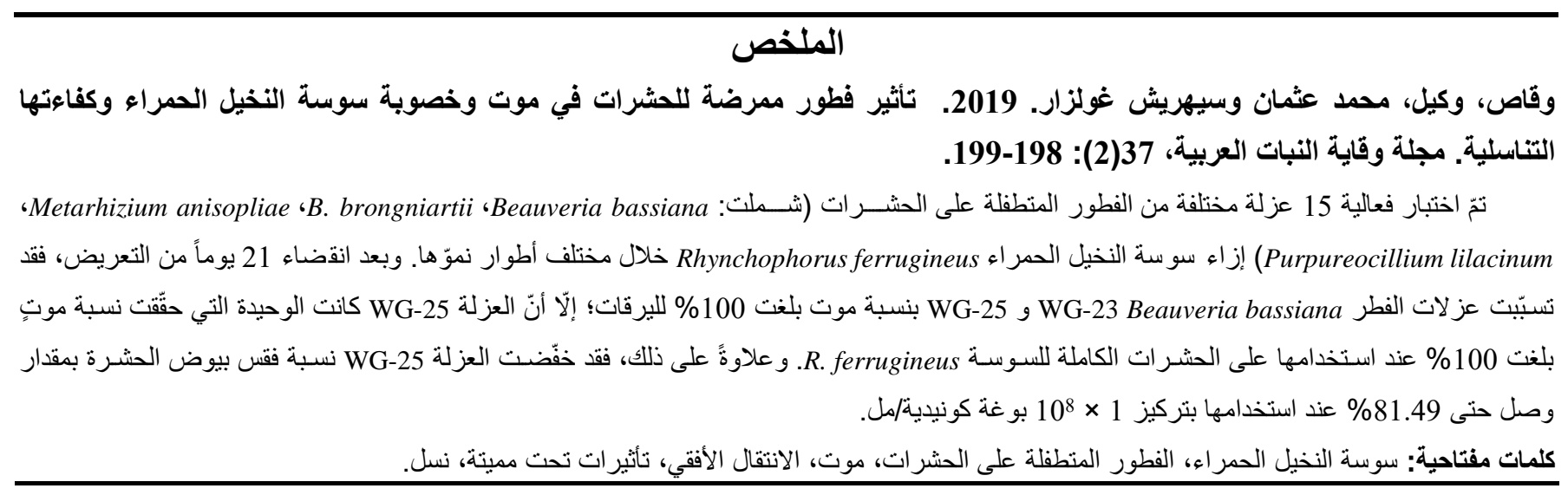

\section{References}

Dembilio, O., E. Quesada-Moraga, C. Santiago-Álvarez and J.A. Jacas. 2010. Potential of an indigenous strain of the entomopathogenic fungus Beauveria bassiana as a biological control agent against the red palm weevil, Rhynchophorus ferrugineus. Journal of Invertebrate Pathology, 104: 214-221. https://doi.org/10.1016/j.jip.2010.04.006

Dembilio, Ó. and J.A. Jaques. 2015. Biology and management of red palm weevil. Pages 13-36. In: Sustainable Pest Management in Date Palm: Current Status and Emerging Challenges, Sustainability in Plant and Crop Protection. W. Wakil, J. R. Faleiro and T. A. Miller (eds.). Springer International Publishing, Switzerland. https://doi.org/10.1007/978-3-319-24397-9

El-Mergawy, R.A.A.M. and A.M. Al-Ajlan. 2011. Red palm weevil, Rhynchophorus ferrugineus (Olivier): economic importance, biology, biogeography, and integrated pest management. Journal of Agricultural Science and Technology, 1: 1-23.

Francardi, V., C. Benvenuti, P.F. Roversi, P. Rumine and G. Barzanti. 2012. Entomopathogenicity of Beauveria bassiana (Bals.) Vuill. and Metarhizium anisopliae
(Metsch.) Sorokin isolated from different sources in the control of Rhynchophorus ferrugineus (Olivier) (Coleoptera Curculionidae). Redia. XCV: 49-55.

Mohan, L.M. 1917. Rept. Asst. Prof. Entomol; Rept. D Sagr. Punjab, for the year ended 30 ${ }^{\text {th }}$ June, 1917.

Tagliavia, M., E. Messina, B. Manachini, S. Cappello and P. Quatrini. 2014. The gut microbiota of larvae of Rhynchophorus ferrugineus Oliver (Coleoptera: Curculionidae). BMC Microbiology, 14: 136. https://doi.org/10.1186/1471-2180-14-136

Verde, G. L., L. Torta, V. Mondello, C.G Caldarella, S. Burruano and V. Caleca. 2015. Pathogenicity bioassays of isolates of Beauveria bassiana on Rhynchophorus ferrugineus. Pest Management Science, 71: 323-328. https://doi.org/10.1002/ps.3852

Wakil, W., J.R. Faleiro and T.A. Miller. 2015. Sustainable Pest Management in Date Palm: Current Status and Emerging Challenges, Sustainability in Plant and Crop Protection. Springer International Publishing, Switzerland. $445 \mathrm{pp}$. https://doi.org/10.1007/978-3-319-24397-9 